\title{
A IMPORTÂNCIA DA RELAÇÃO ENTRE MÃE E FILHO PARA O BOM DESENVOLVIMENTO DO SER HUMANO
}

\author{
Fabiana Zanardo Ferreira, Fabio Camargo Bandeira Villela \\ Universidade Estadual Paulista - UNESP, Pedagogia, Presidente Prudente, SP. Email: fabianazanardo@gmail.com. Bolsa \\ Núcleo de ensino, PROGRAD
}

\section{RESUMO}

O pediatra e psicanalista inglês Donald Woods Winnicott dedicou muito de suas obras e estudos sobre a relação entre mãe e filho. Para ele, a mãe biológica é a pessoa mais adequada para lidar com os cuidados de seu progênito, pois tem uma pré-disposição para tal função e seu corpo e sua mente são preparados para receber o bebê ainda na gestação. $O$ presente artigo traz alguns pontos importantes de sua visão acerca da relação entre a mãe e seu bebê. Percorre o conceito de mãe suficientemente boa, as três funções essenciais da mãe e a relação na hora da amamentação. Destaca-se, entretanto, que, por diversos fatores, o bebê pode não dispor de uma mãe para cuidar dele, o que não o impede, no entanto, de ter um bom desenvolvimento emocional.

Palavras-Chave: relação mãe - filho, Winnicott, Psicanálise, mãe suficientemente boa, holding.

\section{THE IMPORTANCE OF THE RELATIONSHIP BETWEEN MOTHER AND CHILD TO THE GOOD DEVELOPMENT OF THE HUMAN BEING}

\begin{abstract}
The English pediatrician and psychoanalyst Donald Woods Winnicott devoted much of his work and study to the relationship between mother and child. For him, the biological mother is the most appropriate person to deal with the care of her offspring, because she is pre-disposed to this function and her body and mind are ready to receive the baby while still in the gestation. The present article highlights some important points of his view of the relationship between a mother and her baby. There are three essential functions of the mother and her relationship at the time of breastfeeding running through the concept of an adequate mother. However, it should be noted that, for many reasons, the baby may not have a mother to care for him which need not prevent him from having good emotional development.
\end{abstract}

Keywords: mother-child relationship, Winnicott, Psychoanalysis, good-enough mother, holding 


\section{INTRODUÇÃO}

Ao nascer, a criança encontra-se indefesa e depende de alguém que atenda às suas necessidades. Winnicott postula que a pessoa mais apta a prover um ambiente adequado à criança e fornecer-Ihe um suporte necessário para seu desenvolvimento é a mãe. A relação entre mãe e filho acontece de forma natural e eles ajustam-se entre si. Enquanto a criança precisa de cuidados ao nascer, a mãe entra no que Winnicott chama de estado de preocupação materna primária (WINNICOTT, 2000): torna-se dedicada aos cuidados de seu filho e apresenta grande capacidade de adaptar-se às necessidades da criança.

Sabe-se que nem sempre a criança tem a possiblidade de ter à sua disposição uma mãe ou, ainda, uma mãe que lhe seja dedicada, o que não quer dizer que essa criança não terá a possibilidade de ter um desenvolvimento sadio. Nos casos em que a mãe não está presente, tanto a criança como o ambiente terão o desafio de continuar a busca por esse desenvolvimento saudável e desejável.

Este estudo teve como objetivo discutir alguns pontos importantes para a assimilação da relação entre mãe e filho na perspectiva de Winnicott.

\section{METODOLOGIA}

A presente pesquisa, de natureza bibliográfica, tem a intenção de discutir, com base na teoria psicanalítica de Winnicott, a importância do vínculo materno em relação ao bebê nos primeiros meses de vida. A saudável relação entre mãe e filho, para esse autor, é fator muito favorável para um bom desenvolvimento emocional. A partir de argumentos encontrados em sua obra, esse artigo foi estruturado de forma a pensar essa relação e a contribuição que promove para o desenvolvimento emocional da criança. A abordagem temática não exclui, evidentemente, a possibilidade de haver um bom desenvolvimento emocional da criança na ausência da mãe e especialmente da mãe biológica, mas não trata dessa questão como objeto, por excelência, da presente investigação.

\section{RESULTADOS}

Na teoria winnicottiana bebê e mãe formam uma unidade indissociável: não podemos compreender um sem o outro, exceto em estados patológicos, ou ainda excepcionais, quando o bebê não é cuidado e acompanhado por sua mãe, e sim por outra pessoa que assuma essas funções.

A mãe tem a função de prover para o seu filho um ego auxiliar; é dessa forma que será provocada nele tal integração. É através do cuidado materno e das sensações de satisfação sentidas pelo ser humano no princípio da vida que fazem com que ele tenha um desenvolvimento satisfatório e passe de um ser não integrado para um ser integrado (WINNICOTT, 1990)

O bebê, ao nascer, é um ser não integrado, o que é diferente de um ser desintegrado. A desintegração é a ausência da integração e não está ligada diretamente ao estágio inicial do bebê. No período de não integração (WINNICOTT, 1990), os núcleos do ego estão desordenados e falta a consciência de si. Existe uma tendência biológica para a integração, mas ela é também estimulada pelo cuidado ambiental.

Para que forme seu self verdadeiro ${ }^{1}$, é preciso que a criança passe por experiências em que ela própria é o sujeito e é a mãe quem usualmente lhe propicia essas experiências, por meio de

\footnotetext{
${ }^{1}$ Self é o que é próprio de cada pessoa, o seu cerne. Para Winnicott, o self verdadeiro está ligado a uma base psicossomática e se expressa como gesto espontâneo e se fortalece com a adaptação da mãe aos gestos e alucinações do bebê, em oposição à adaptação ou à submissão do bebê às exigências ambientais. Da expressão do self verdadeiro decorre uma sensação de existir e de integridade e com base na qual a criatividade é possível. O falso self, apresentaria características opostas, como renúncia psíquica daquilo que é próprio da pessoa e de sua experiência pulsional em prol de uma adaptação subserviente às exigências do ambiente - nos primeiros anos de vida, representado, em geral, pela mãe -, do que decorreria o sentimento de não existência e de ausência de autenticidade. Não há apenas oposição entre falso self e self verdadeiro, mas também articulação entre eles, servindo o falso self de mecanismo de defesa e de proteção do self verdadeiro, embora às custas de um efetivo desenvolvimento emocional. (WINNICOTT, 1983)
} 
seus cuidados suficientemente bons. Quando a mãe consegue ser suficientemente boa, ajuda seu bebê a formar a sua base de fazer criativo: o bebê tem a sensação de que ele é quem cria o mundo ao seu redor e até certo ponto de onipotência, o que será especificado adiante.

O que torna a mãe suficientemente boa não são suas referências ou algum preparo antecedente. Uma compreensão intelectual de sua tarefa não importa, o fator biológico já a deixa preparada para lidar com seu filho da melhor forma possível. Nos primeiros anos de vida, existe uma quase completa adaptação da mãe às necessidades do bebê, o que decresce de modo gradativo e também de forma natural (WINNICOTT, 1975). Notam-se diferenças biológicas entre meninas e meninos, até mesmo nas brincadeiras da infância, quando é mais comum deparar-se com uma menina brincando de embalar uma boneca, alimentar e cuidar dela. Essas brincadeiras não estão relacionadas ao tornar-se mulher, mas em tornar-se uma mãe boa e dedicada (WINNICOTT, 2008), o que extrapolaria a mera influência ambiental.

A devoção da mãe, nesse caso, é mais significativa que a compreensão racional que ela tem do que significa ser uma boa mãe. A mãe devotada não é a mãe utópica, que nunca falha ou não espera que seu filho precise de algo para lhe dar. Ela atende às necessidades do filho conforme sente que ele precisa delas. Vez ou outra deixa que espere um pouco pelo que anseia e o acompanha em suas necessidades; assim, ajuda-o a constituir-se como um ser autônomo.

O bebê não quer tanto que Ihe dêem a alimentação correta na hora exata como, sobretudo, ser alimentado por alguém que ama alimentar seu próprio bebê. $O$ bebê aceita como coisas naturais a maciez das roupas ou a temperatura correta da agua do banho. O que ele não pode dispensar é o prazer da mãe que acompanha o ato de vestir ou de dar banho ao seu próprio bebê. Se tudo isso lhe dá prazer, é algo como o raiar do sol para o bebê. $O$ prazer da mãe tem que estar presente nesses atos ou então tudo o que fizer é monótono, inútil e mecânico. (WINNICOTT, 2008, p.28)

Segundo Winnicott, a maternagem suficientemente boa pode ser sintetizada dentro de três funções essenciais exercidas pela mãe nos primeiros meses de vida de seu filho: holding (sustentação), handling (manejo) e a apresentação dos objetos.

_Às ações com que a mãe atende às necessidades de seu filho, o cuidado e a disposição empática que é dedicada ao bebê cotidianamente Winnicott deu o nome de holding (sustentação). A sustentação compreende a sensibilidade com que se lida e a forma como entende o que ele sente (WINNICOTT, 1990). O holding é mais do que a experiência física, considera a forma como o bebê sente-se acolhido e seguro nos braços de sua mãe. Ela o compreende de forma diferente das pessoas ao redor, mesmo que sejam pessoas que gostem de crianças ou tenham contato sempre com o bebê: a forma como a mãe reconhece essas necessidades é única.

À forma como a mãe segura seu bebê, dá banho e o toca na hora de exercer suas funções, dá-se o nome de handling (manejo). O handling é o contato que a mãe tem com as diversas partes do corpo de seu filho e a sensação sentida no toque da pele do bebê. A mãe que segura seu filho nos braços constrói uma forma de amar e de proteger contra as afrontas psicológicas e, quando essa sustentação é bem-sucedida, a criança vive uma continuidade existencial satisfatória. "O objetivo dos cuidados maternos não está limitado ao estabelecimento de saúde na criança, mas inclui o fomento de condições para a experiência mais rica possível, com resultados a longo prazo na profundidade e valor crescente de caráter e personalidade do indivíduo" (WINNICOTT, 2008, p.63)

Quando o bebê está esperando por um objeto e a mãe lhe oferece o seio ou a mamadeira, ele experimenta a ilusão de que esse objeto foi criado por ele. A mãe, que está sempre à disposição, faz com que essa ilusão seja reforçada. Assim, ele se sente onipotente, capaz de lidar com suas tensões fisiológicas ou com a dor, protegendo-se de certas angústias. Em certo 
momento, a mãe passa a apresentar ao seu bebê possíveis substitutos dela própria, não deixa de prover os cuidados, apresentando-Ihe a capacidade que ele mesmo tem em criar novos objetos. Cada pequeno indivíduo tem sua capacidade emocional para lidar com essas mudanças.

O objeto escolhido pelo bebê para ser uma representação do seio ou até mesmo da própria mãe Winnicott chamou de Objeto Transicional, que aparece psiquicamente em fase onde o bebê passa do controle onipotente para o controle pela manipulação (WINNICOTT, 1975). Esse objeto deve ser respeitado como algo muito importante para a criança e não deve ser trocado, a menos que seja por ela própria. Até mesmo o ato de limpar esse objeto pode romper a ligação entre ele e a criança.

A primeira mamada teórica é uma junção das primeiras mamadas do bebê (WINNICOTT, 1990) e tem grande importância para mãe e filho, pois as subsequentes se constituem através dela; então, se a experiência for boa, as outras, consequentemente, tendem a ser igualmente boas; se não for, as outra tendem a ser também insatisfatórias ou frustrantes.

Esta primeira mamada teórica é também a primeira mamada real, exceto pelo fato de que a experiência real não é tanto um acontecimento singular quanto uma construção do evento a partir da memória. É possível dizer que devido à extrema imaturidade do bebê recém-nascido, a primeira mamada não pode ser significativa como experiência emocional. No entanto, não há dúvida de que se a primeira mamada ocorre satisfatoriamente, estabelece-se um contato, de modo que o padrão das mamadas se desenvolve a partir dessa primeira experiência. (WINNICOTT, 1990, p.120)

O bebê começa a ter capacidade imaginativa a partir das primeiras mamadas. Com o passar do tempo, passa a ter confiança no objeto (seio) e que esse irá aparecer ou desaparecer conforme ele sinta necessidade. É a sensação de onipotência, expressa na ideia de que o mundo ao seu redor é criado por ele próprio.

Pode ocorrer, por algum motivo, como a ausência da mãe ou até mesmo de uma mãe que está impossibilitada de amamentar, que a criança não tenha contato com o seio. Isso não constitui um enorme problema para o bebê: conforme Winnicott, ele poderá ser alimentado por meio da mamadeira e estabelecer dessa forma a relação com a mãe. Ainda assim, as mães que conseguem amamentar encontram para si uma experiência muito mais rica no ato da amamentação e, de alguma forma, isso contribui para que as relações entre bebê e mãe se estabeleçam mais cedo (WINNICOTT, 2008).

O que pode ser considerado como uma experiência negativa para o bebê é a alimentação forçada. A mãe não deve tentar inserir o seio ou a mamadeira na boca do filho em um momento em que ele não demostra apetite ou interesse de brincar com eles. Quando ele recebe o objeto no momento em que está com fome, suga o leite e a sensação é agradável. Mas se passa, em instantes, a recusar esse objeto, e não consegue livrar-se dele, isso representa para a criança uma ameaça, que vai interferir no modo como ela imagina o mundo ao seu redor e na formação do seu verdadeiro self. Se a mãe substitui um gesto espontâneo de seu filho e faz com que ele se submeta a um gesto dela própria, é o início da formação do falso self.

O falso self pode ser desenvolvido nesse período de maior dependência da mãe, quando a criança não tem oportunidade de criar o ambiente ao seu redor e vive em uma situação de submissão a tudo o que lhe é imposto.

A mãe deve, portanto, conseguir atuar como alicerce para a adaptação do bebê para o mundo, para que ele seja capaz de experimentar a sensação de onipotência tão importante para o seu desenvolvimento e que lhe apresente o mundo externo progressivamente. Quando consideramos que a mãe suficientemente boa não está presente, seu substituto nos cuidados 
destinados ao bebê deve buscar suprir as necessidades da criança, dando a ela a chance de se desenvolver de forma sadia, tornando-se uma pessoa adulta autônoma e com boas relações, ainda que, em tese, seja a mãe a pessoa mais adequada para esses cuidados. A usual vantagem da mãe para a criança em relação a seus substitutos é claramente discutida por Winnicott:

Seu amor por seu próprio bebê provavelmente é mais verdadeiro, menos sentimental do que o de qualquer substituto; uma adaptação extrema às necessidades do bebê pode ser feita pela mãe real sem ressentimento. É ela quem está em condições de preservar todos os pequenos detalhes de sua técnica pessoal, fornecendo assim ao bebê um ambiente emocional simplificado (que inclui os cuidados físicos). (WINNICOTT, 1990, p. 132)

\section{DISCUSSÃO}

O desenvolvimento primitivo infantil passa por inúmeros momentos, até que a criança se constitua como um indivíduo com personalidade. No processo do seu desenvolvimento, é necessário que ela tenha suporte para que ocorra a integração de seu ego e seja capaz de perceber a diferenciação entre o eu e o mundo exterior. Esse período de diferenciação deve ser visto com muito cuidado: nele, o que vem do exterior pode ser sentido como algo ameaçador para o bebê. Com o cuidado materno amoroso, essa ameaça passa a ser neutralizada.

A mãe é a pessoa mais adequada para exercer os cuidados iniciais com o seu filho devido ao preparo emocional que tem desde a concepção: para Winnicott, a mãe passa a acreditar que o centro do mundo está situado em seu próprio corpo. Mesmo que tenha passado por uma fase inicial aborrecida ou estressante, a mãe acaba por direcionar seus sentimentos à sua gestação.

Existem casos em que, por alguma adversidade, o bebê cresce sem a mãe biológica. Se ele for inserido em um bom ambiente, com amor, carinho e firmeza, pode desenvolver-se de forma positiva e tornar-se um adulto independente e sem complicações emocionais, mas sua necessidade ainda será a de que alguém lhe apresente o mundo em pequenas doses, suprindo suas necessidades físicas e emocionais. A mãe tende a ter fatores próprios que facilitam esse desenvolvimento.

\section{CONCLUSÃO}

O desenvolvimento humano primitivo é um processo bastante complexo e com muitas especificidades. É um período em que o genitor deve estar muito atento à criança pela qual é responsável. É a partir das relações estabelecidas nesse período que se definem como serão as relações futuras, a integração do ego e o desenvolvimento da personalidade do indivíduo.

Para que a criança caminhe bem em seu desenvolvimento emocional, necessita de algo que mereça sua confiança e que nutra sentimentos bons por ela. Outra pessoa que não seja a mãe biológica terá dificuldades maiores para adaptar--se às necessidades do bebê e da criança.

A mãe passa todo o período da gestação adaptando-se física e psicologicamente para receber seu bebê e dedicar a ele os cuidados necessários; sente-se insegura, espera e cria expectativas em certos momentos em relação ao ser que está gerando. E, ao nascer o bebê, é essa mãe em sintonia com seu filho que tende a estar em posição privilegiada para prover cotidianamente os seus cuidados. A experiência dessa importante relação é rica igualmente para a mãe e seu filho.

\section{REFERÊNCIAS}

WINNICOTT, W. A criança e o seu mundo. 6. ed. Rio de Janeiro: Zahar, 2008.

. Natureza humana. S. ed. 6. ed. Rio de Janeiro: Imago, 1990. 
O brincar e a realidade. Rio de Janeiro: Imago, 1975.

. Da Pediatria à Psicanálise - Obras escolhidas. Rio de Janeiro: Imago, 2000.

. O ambiente e os processos de maturação - Estudos sobre a teoria do desenvolvimento emocional. Porto Alegre: Artmed, 1983. 